\title{
Cultura Política Brasileira
}

\author{
Brazilian Political Culture
}

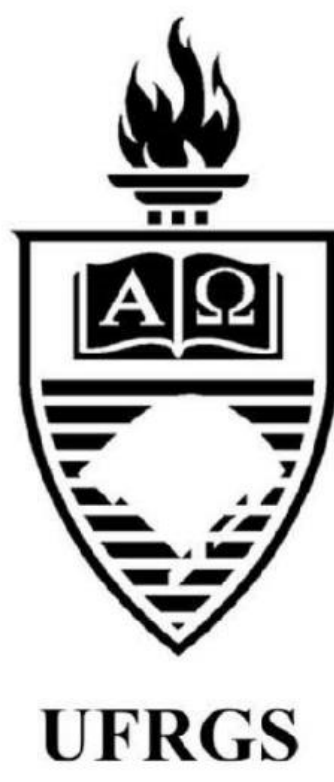

\section{Christian Edward Cyril Lynch}

Universidade Estadual do Rio de Janeiro 


\title{
Cultura política brasileira
}

\author{
Brazilian Political Culture
}

Christian Edward Cyril Lynch*

\section{REFERÊNCIA}

LYNCH, Christian Edward Cyril. Cultura política brasileira. Revista da Faculdade de Direito da UFRGS, Porto Alegre, n. 36, p. 4-19, ago. 2017.

\section{RESUMO}

Trata-se de uma introdução teórica ao pensamento político brasileiro, na forma didática de verbete, com a seguinte ementa: Política e cultura política brasileira - A cultura política europeia e seus grandes temas: autoridade, liberdade e igualdade. - A expansão colonial europeia e a conformação da cultura política periférica. - A cultura política ibero-americana e o tema do atraso. - A orientação modernizadora da cultura política brasileira. - A importação das instituições dos países cêntricos como indutor da modernização. - Os modelos cêntricos: Inglaterra, França e Estados Unidos. - A inefetividade institucional: a dicotomia país legal versus país real. - A percepção da defasagem entre instituições e realidade: três diagnósticos. - Primeiro diagnóstico: atraso do país legal em face do país real. - Segundo diagnóstico: inefetividade do país legal sobre o real. - Terceiro diagnóstico: adiantamento demasiado do país legal diante do real. - A frustração em torno da modernização institucional: o pedagogismo. - Reação à crise de legitimidade da política tradicional: as vanguardas modernizadoras. - As vanguardas burocráticas (1): o governante. - As vanguardas burocráticas (2): os militares. - As vanguardas burocráticas (3): a magistratura e o ministério público. - Ideologias políticas brasileiras. - Ideologias políticas (1): o nacionalestatismo. - Ideologias políticas (2). O liberalismo cosmopolita.

\section{PALAVRAS-CHAVE}

Pensamento político brasileiro. Cultura política. Pensamento social brasileiro. Teoria política. Póscolonialismo. Transplantes jurídicos.

\section{ABSTRACT}

This is a theoretical introduction to Brazilian political thought, in the didactic form of entry, with the following syllabus: Politics and Brazilian political culture. European political culture and its major themes: authority, freedom and equality. - European colonial expansion and the configuration of peripheral political culture. - The Ibero-American political culture and the theme of backwardness. - The modernizing orientation of Brazilian political culture. - Importation of centric countries's institutions as inductor of modernization. - The central models: England, France and the United States. Institutional ineffectiveness: the legal country versus real country dichotomy. - The perception of the gap between institutions and reality: three diagnoses. - First diagnosis: delay of the legal country in relation to the real country. Second diagnosis: ineffectiveness of the legal country over the real country. - Third diagnosis: excessive development of the legal country before the real country. - The frustration surrounding institutional modernization: pedagogism. - Reaction to the crisis of legitimacy of traditional politics: the modernizing vanguards. - The bureaucratic vanguards (1): the ruler. - The bureaucratic vanguards (2): the military. - The bureaucratic vanguards (3): the judiciary and public ministry. - Brazilian political ideologies. - Political ideologies (1): the national-statism. - Political ideologies (2). The cosmopolitan liberalism.

\section{KEYWORDS}

Brazilian political thought. Political culture. Brazilian social thought. Political theory. Post-colonialism. Legal transplants.

\section{SUMÁRIO}

Política e cultura política brasileira. A cultura política europeia e seus grandes temas: autoridade, liberdade e igualdade. A expansão colonial europeia e a conformação da cultura política periférica. A cultura política ibero-americana e o tema do atraso. A orientação modernizadora da cultura política brasileira. A importação das instituições dos países cêntricos como indutor da modernização. Os modelos cêntricos: Inglaterra, França e Estados Unidos. A inefetividade institucional: a dicotomia país legal versus país real. A percepção da defasagem entre instituições e realidade: três diagnósticos.

\footnotetext{
* Professor do Instituto de Estudos Sociais e Políticos da Universidade do Estado do Rio de Janeiro (IESP-UERJ) e pesquisador da Fundação Casa de Rui Barbosa (FCRB). Pesquisador do CNPq e da FAPERJ. Doutor em Ciência Política pelo Instituto Universitário de Pesquisas do Rio de Janeiro (IUPERJ).
} 
Primeiro diagnóstico: atraso do país legal em face do país real. Segundo diagnóstico: inefetividade do país legal sobre o real. Terceiro diagnóstico: adiantamento demasiado do país legal diante do real. A frustração em torno da modernização institucional: o pedagogismo. Reação à crise de legitimidade da política tradicional: as vanguardas modernizadoras. As vanguardas burocráticas (1): o governante. As vanguardas burocráticas (2): os militares. As vanguardas burocráticas (3): a magistratura e o ministério público. Ideologias políticas brasileiras. Ideologias políticas (1): o nacional-estatismo. Ideologias políticas (2). O liberalismo cosmopolita. Referências.

\section{POLÍTICA E CULTURA POLÍTICA}

A política repousa sobre o dado da pluralidade humana no contexto de uma comunidade composta de seres de múltiplas crenças e interesses, sendo por seu intermédio que indivíduos e grupos negociam, implantam e asseguram o cumprimento das diferentes demandas que formulam entre si ou face da coletividade. Por cultura política, entenderemos aqui o conjunto de discursos ou práticas simbólicas por que tais demandas são efetuadas, conferindo identidades aos indivíduos e grupos, indicando-lhes os limites de suas comunidades e definindo as posições a partir das quais podem demandar. Ela constitui os significados dos conceitos e das palavras por que essas demandas são elaboradas, a natureza dos contextos de sua produção e a autoridade dos princípios a que elas se vinculam. Além disso, a cultura política condiciona o modo de organização e compreensão das instituições, modelando as constituições e os poderes das agências nelas previstas, bem como os procedimentos de resolução dos litígios e cumprimento das decisões que dela resultam. A própria construção da figura da autoridade política em uma comunidade é uma questão de autoridade linguística inerente à cultura política, já que as funções políticas são definidas como legítimas e como tal alocadas a partir dos discursos ou ideologias políticas existentes no seu interior.

\section{A CULTURA POLÍTICA EUROPEIA E SEUS GRANDES TEMAS: AUTORIDADE, LIBERDADE E IGUALDADE}

Em sua origem a cultura política moderna está vinculada à emergência do Estado-Nação europeu, entendido como uma resposta à crise da unidade moral do mundo cristão no contexto das guerras religiosas do século XVI e à fragmentação, anarquia e insegurança dela resultantes. Por meio de ideologias de valorização da ordem monárquica - como a do absolutismo e a da razão de Estado -, os príncipes conseguiram estabelecer a paz interna a partir de uma ordem autoritária centralizada sobre o território do reino (o "Estado"). Depois disso, o Estado sofreria duas grandes transformações. A prosperidade decorrente da consolidação da ordem monárquica suscitou a emergência de novos setores que, orientados por ideologias de valorização da ordem oligárquica - o republicanismo e o liberalismo -, converteram no século XIX o Estado autocrático em constitucional representativo (o "Estado liberal"). A segunda grande transformação teve lugar no século XX e, alimentada por ideologias igualitárias, como o liberalismo social e o socialismo democrático, democratizaram a ordem liberal oligárquica anterior e redimensionaram o Estado para que ele pudesse promover a redução das desigualdades sociais (o "Estado democrático"). A cultura política moderna acompanhou aquelas mudanças, articulando-as no plano ideológico e institucional, consagrando os três valores de que o Estado se fez garantidor: o da autoridade do poder público, o da liberdade do 
indivíduo e o da igualdade do cidadão. As grandes correntes correspondentes a cada uma delas - o autoritarismo, o liberalismo e o socialismo - se subdividem em outras, mais ou menos aparentadas e eventualmente combinadas, conformando um espectro político de tendências diversas, da mais reacionária à mais radical.

\section{A EXPANSÃO COLONIAL EUROPEIA E A CONFORMAÇÃO DA CULTURA POLÍTICA PERIFÉRICA}

A hegemonia da cultura política moderna e de suas ideologias constitutivas se impôs pelos demais continentes do planeta no bojo da expansão colonial europeia, decorrente da lógica imperialista da sua economia e da superioridade do seu poder militar. Assimilada como um esquema de ordem e sentido progressivos, organizador dos lugares das diversas nações ao longo do tempo, a filosofia da história desde o século XVIII explicava o papel dos diversos povos e a função de suas culturas no processo "universal" de "civilização". Orientadas para um futuro de paz, riqueza, liberdade e igualdade, haveria nações no "centro" do mundo, "mais adiantadas", "civilizadas", que marchavam à frente, produzindo ciência, arte e verdade. Outras, porém, estavam na periferia do mundo, sendo "atrasadas", "bárbaras", devendo seguir os exemplos e os modelos das primeiras para se "adiantarem". Era essa suposta superioridade da cultura europeia que justificava o colonialismo exercido por suas potências sobre as áreas que se achavam à sua periferia. Tal expansão produziu resultados que variaram em função de fatores como a época em que a expansão se processou, os agentes metropolitanos que a produziram, o tipo de cultura autóctone sobre a qual ela incidiu, e do seu maior ou menor grau de absorção pela de origem europeia. A eventual resistência das populações autóctones na América, na África e na Ásia não as impediu de assimilarem a cultura europeia, condição mesma para a aquisição dos meios necessários ao seu fortalecimento e posterior independência; da mesma forma, à emancipação seguiu-se a tentativa por eles perseguida desconstruírem seus Estados adaptando as ideologias e experiências históricas europeias. A cultura política dos países periféricos surgiu, portanto, produzida por uma elite colonial que se esforçava para apreender a sua realidade local a partir do instrumental analítico fornecido pela cultura política europeia, isto é, "cêntrica".

\section{A CULTURA POLÍTICA IBERO- AMERICANA E O TEMA DO ATRASO}

$\mathrm{Na}$ América Ibérica, em particular, a elite colonial estava umbilicalmente vinculada à cultura europeia, pela sua condição de descendente do europeu colonizador. Valendo-se dos valores europeus e de seus pressupostos etnocêntricos, julgados de alcance e validade universais, aquela elite tendia a perceber-se e à realidade que a circundava como culturalmente exótica, qualitativamente inferior e temporalmente atrasada. Absorvida pela maior parte das elites ibero-americanas, essa concepção que distinguia as nações por critérios de tempo (presente/passado) e lugar (centro/periferia) repercutiu na definição de suas identidades nacionais, na forma de um complexo de inferioridade. $\mathrm{O}$ etnocentrismo da cultura política europeia a levava a ver a maior parte das características de sua terra, que destoavam daquelas descritas como adequadas pelos autores europeus - geografia, o clima, as combinações étnicas da população, as técnicas de cultivo, as práticas religiosas -, como negativas. As diferenças quantitativas entre as nações do "centro" e da "periferia", medidas objetivamente em termos de tecnologia ou poder militar, converteram-se em diferenças qualitativas no plano da existência: aquilo que era apenas um 
juízo de fato (assimetria militar e econômica) se transformou, no plano das representações sociais, num juízo de valor (inferioridade no plano da existência e da cultura).

\section{A ORIENTAÇÃO MODERNIZADORA DA CULTURA POLÍTICA BRASILEIRA}

Entendida no quadro mais amplo da América Ibérica, a cultura política brasileira tem temas característicos. O principal deles é a preocupação com o tema da modernização. A partir do juízo de valor negativo a respeito da realidade nacional, os atores políticos brasileiros extraíram e ainda extraem o imperativo de modernizar o país, de molde a reduzir a distância que separa a sua sociedade daquela dos países cêntricos, vista por eles - de modo algo idealizado, diga-se de passagem - como padrão de normalidade. A modernização ou desenvolvimento se torna o objetivo prioritário da agenda política, a ele subordinando-se os demais. Assuntos como estabelecimento da autoridade, da liberdade, ou da democracia só são plenamente valorados na medida em que favorecem ou pelo menos não colidam com o imperativo modernizador. Modernizar significa superar o atraso político pela transformação das estruturas sociais, políticas e econômicas do país, purgandoo de todas as características herdadas da colonização ibérica, reputada responsável pela sua condição atrasada.

\section{A IMPORTAÇÃO DAS INSTITUIÇÕES DOS PAÍSES CÊNTRICOS COMO INDUTOR DA MODERNIZAÇÃO}

Para superar a cultura política do atraso, resultante daquela má formação - católica, absolutista, lusitana, escravista -, era preciso emular a cultura política dos países cêntricos, reputados modelos da modernidade ou da civilização almejada. E essa emulação começava pela transposição das instituições políticas cêntricas para a nossa realidade. A regra segundo a qual as instituições deveriam refletir $\mathrm{e}$ acompanhar o desenvolvimento da sociedade, válida para os países cêntricos, não era válida para os países atrasados. Aqui, organizar as instituições a partir do estado social nos levaria a consagrar o atraso em que já nos encontraríamos. Na periferia, o papel das instituições não seria o de refletir o estado social, que seria atrasado, e sim o de agir sobre ele, a fim de modificá-lo em sentido progressista. Há, portanto, um consenso acerca da premissa de que as instituições políticas e jurídicas devem ser mais adiantadas que o estado social, ficando as disputas em torno do grau de maior ou menor adiantamento que elas deveriam apresentar. Em 1843, o senador Paula Sousa deixou um testemunho admirável das razões que nos impeliam a emular a cultura política dos países cêntricos:

\begin{abstract}
Nós nascemos ontem; passamos do estado de colônia para governo representativo; a nação de que fazíamos parte e de quem éramos colônia não tinha governo representativo; era escrava [i.e. absolutista] e até muito atrasada na escala da civilização; logo, para marcharmos, havemos de tomar por modelo e por norte essa grande nação [a Inglaterra], que lutou séculos para conseguir o governo representativo, e que desde 1688 o tem estável e glorioso, e cada vez mais firmando e desenvolvendo as regras desta forma de governo ${ }^{1}$.
\end{abstract}

\section{OS MODELOS CÊNTRICOS: INGLATERRA, FRANÇA E ESTADOS UNIDOS}

Os modelos de países modernos a serem emulados no Brasil para fomentar o progresso brasileiro e retirá-lo do atraso foram quase sempre três: a Inglaterra, França e Estados Unidos. A Inglaterra era a favorita de liberais como o senador Costa Ferreira, para quem, em 1840, os ingleses haviam "elevado a sua nação ao maior 
grau possível de felicidade, força e glória, como na terra se não encontra nação alguma" ${ }^{2}$. Essa admiração chegaria ao ápice meio século depois na opinião de Rui Barbosa, no início da década de 1890: "Na obra da civilização ocidental não há, talvez, mais que três papéis supremos: o da Judéia, berço do monoteísmo e do Cristo; o da Grécia, criadora das artes e da filosofia; o da Inglaterra, pátria do governo representativo e mãe das nações livres: bendita esta raça providencial". ${ }^{3}$ Já a França era preferida por aqueles de viés mais estatizante, ou que destacavam o seu papel como matriz civilizatório do mundo, como o conservador Visconde de São Lourenço, para quem, em 1871, àquela nação se devia "mais da metade do bem da civilização a que temos chegado"; ela era "a grande nação latina que marcha à frente dos povos desta raça a que nós pertencemos" 4 . Os Estados Unidos, porém, também encantavam a elite política brasileira, por serem vistos como a materialização americana da invejada civilização inglesa. O senador Lopes Gama afirmava já em 1839: "Citamos todos os dias aqui os Estados Unidos como modelo"5. Oitenta anos depois, o próprio Presidente da República, Epitácio Pessoa, lançaria mão daqueles argumentos para explicar por que o Brasil haveria de seguir, em matéria de política internacional tudo o que fosse decidido por aqueles três países: "O Brasil deve a essas nações o seu rápido progresso, o seu desenvolvimento considerável; ele as ama, ele as respeita, ele não pode deixar de segui-las na solução de seus problemas de ordem geral" ${ }^{6}$. Depois de 1930, o quadro variaria um pouco, passando os Estados Unidos a concentrar a atenção outrora voltada para a França e para a

\footnotetext{
${ }^{2}$ ANAIS do Senado do Império, sessão de 19 de junho de 1840 .

${ }^{3}$ BARBOSA, Rui. Correspondência. Coligida, revista e anotada por Homero Pires. São Paulo: Saraiva, 1932. p. 94.

${ }^{4}$ ANAIS do Senado do Império, sessão de 22 de julho de 1871.

${ }^{5}$ ANAIS do Senado do Império, sessão de 2 de julho de 1839.
}

Inglaterra, ao passo que os comunistas voltariam a sua atenção para a União Soviética.

\section{A INEFETIVIDADE INSTITUCIONAL: A DICOTOMIA PAÍS LEGAL VERSUS PAÍS REAL}

Outro tema típico da cultura política brasileira, derivado da exigência da modernização, é o da distância entre as suas instituições políticas, inspiradas nas constituições dos países cêntricos, e o seu rendimento deficiente ou nulo no plano da sociedade local. Às vésperas da República, em 1889, Eduardo Prado se referia a este hiato entre instituições e sociedade como "o fato culminante da existência política da existência política do Brasil". Trata-se da famosa oposição entre o país legal e o país real. Se as instituições cêntricas impactavam sobre a realidade periférica, a fim de modernizá-las, elas não o faziam na forma nem na velocidade esperada pelo púbico, produzindo efeitos inesperados, às vezes negativos. Prado explicava: "Quem estudar a história do Brasil independente verá a desproporção entre a civilização real do país e o adiantamento das suas instituições originando um desequilíbrio sensível ainda hoje. Os algarismos demonstram que nenhum país dotado de um governo livre apresenta tão grande número de qualidades moralmente negativas quantos são no Brasil os analfabetos, os rústicos isolados no interior e os representantes das raças inferiores ainda não extintas ou anuladas pela absorção na raça civilizada" 7 . O sentimento de frustração, revolta ou apatia decorrente daquela oposição entre país legal e país real está presente nas reflexões de quase todos os observadores da

${ }^{6}$ PESSOA, Epitácio. Conferência da Paz, Diplomacia e Direito Internacional. Obras completas de Epitácio Pessoa, volume XIV. Rio de Janeiro: Instituto Nacional do Livro, 1961, p. 112.

${ }^{7}$ PRADO, Eduardo. Destinos políticos do Brasil. Revista do Instituto Histórico e Geográfico Brasileiro. Anais do Congresso de História do Segundo Reinado. v. II. Rio de Janeiro: 1984, p. 164. 
cena brasileira. A este respeito reclamava Paulo Prado, sobrinho de Eduardo, em 1932: “As nossas crises mais graves encontram logo o remédio salvador que as deve resolver definitivamente. Para ressurgirem em seguida, sob novos aspectos, com novas soluções radicais". Assim teriam sido todas as nossas mudanças: independência, república, revolução de 1930. "A cada uma sucede, porém, o que Silvio Romero chamava, no ritmo da vida nacional, 'o processo da desilusão"”, concluía Prado ${ }^{8}$.

\section{A PERCEPÇÃO DA DEFASAGEM ENTRE INSTITUIÇÕES E REALIDADE: TRÊS DIAGNÓSTICOS}

Essa percepção da defasagem entre as instituições políticas que deveriam fomentar a modernização e a realidade socioeconômica que continuava atrasada despertou diferentes reações. Conforme há pouco referido, havia um consenso implícito de que as instituições políticas aclimatadas ao Brasil deveriam estar um pouco à frente do seu atrasado estado social, para sobre ela produzirem seus salutares efeitos modernizadores. O problema tinha lugar, todavia, quando aquele hiato parecia desmesurado, gerando desordem, autoritarismo ou desigualdade social. Nesse caso, era preciso tentar restabelecer a conexão entre instituições e sociedade: "Se as revoluções procedem da desarmonia entre as ideias e as instituições dos povos, é evidente que todas as vezes que se puderem harmonizar as instituições às ideias, desaparecem as revoluções", reconhecia em 1844 o senador Bernardo Pereira de Vasconcelos. "A sabedoria do governo, a sua previdência, está em saber atalhar as revoluções, satisfazendo as

\footnotetext{
${ }^{8}$ PRADO, Paulo. Paulística, etc. Organização de Carlos Augusto Calil. São Paulo: Companhia das Letras, 2004, p. 291.

${ }^{9}$ ANAIS do Senado do Império, sessão de 23 de maio de 1844.
}

necessidades públicas" ${ }^{9}$. Ao longo da história brasileira, houve pelo menos três percepções ou diagnósticos possíveis do mau funcionamento das instituições, a ensejar reações.

\section{PRIMEIRO DIAGNÓSTICO: ATRASO DO PAÍS LEGAL EM FACE DO PAÍS REAL}

A primeira era a de que as instituições (país legal) estariam atrasadas em relação às necessidades do estado social (país real). Nesse caso, queixando-se de que instituições políticas eram demasiado atrasadas, os atores políticos tenderam a rejeitá-las por seu caráter "retrógrado", pedindo a sua adequação ou substituição. Este foi o caso de liberais do Império como Tavares Bastos, que em 1862 condenava o modelo conservador do Segundo Reinado como autoritário e descompassado com a civilização europeia. Tratava-se de um governo "herdeiro dos bem-aventurados ministros do Reino Unido de Portugal, Brasil e Algarves"; "governo de retardo" que deveria ser substituído por outro, moderno, americano e audaz ${ }^{10}$. A crítica do anacronismo das instituições políticas foi repetida cerca de cinquenta anos depois, em sentido inverso, pelos autoritários do Estado Novo. Para Francisco Campos, o liberalismo da Primeira República, gestado por Tavares Bastos, estava condenado a desaparecer diante dos desafios opostos pela emergência das massas na cena política, que exigiam, para ser enfrentados, um Estado de tipo autoritário, análogo àqueles que se construíam nos países cêntricos: "Nos velhos moldes e através de antiquadas formulas institucionais", ele afirmava em 1941, "seria impossível assegurar a existência e o progresso da Nação" ${ }^{11}$. A crítica do anacronismo institucional

10 BASTOS, Aurelino Cândido Tavares. Cartas do Solitário. São Paulo: Companhia Editora Nacional, 1976, pp. 103 e 203.

${ }^{11}$ CAMPOS, Francisco. O Estado Nacional: sua estrutura, seu conteúdo ideológico. $3^{\text {a }}$. edição. Rio de Janeiro: Livraria José Olímpio, 1941, p. 36. 
provocado pelo desenvolvimento das forças socioeconômicas seria também a tônica de radicais de esquerda, como Osny Duarte Pereira, que às vésperas do golpe de 1964 entendia que a Constituição de 1946 precisava "ser alterada, para poder cumprir sua missão, dentro da hora histórica que estamos vivendo" 12 . O próprio presidente João Goulart, no comício da Central do Brasil, advogou "a necessidade de revisão da Constituição [de 1946], que não atende mais aos anseios do povo $\mathrm{e}$ aos anseios do desenvolvimento desta Nação"13.

\section{SEGUNDO \\ DIAGNÓSTICO: INEFETIVIDADE DO PAÍS LEGAL SOBRE O REAL}

O segundo diagnóstico possível era o de que, embora as instituições (o país legal) estivessem em consonância com as necessidades do estado social (país real), elas não adquiriam efetividade: não "pegavam", não saiam do papel. Conforme proviesse dos conservadores ou dos progressistas, esse diagnóstico de inefetividade institucional suscitava diferentes reações. $\mathrm{Na}$ Primeira República, conservadores como Campos Sales e Alcindo Guanabara se resignavam com a realidade oligárquica que os aproveitava, alegando que a causa daquela defasagem não estava nas instituições, que eram boas, mas na realidade social. Era o que afirmava Guanabara em 1902: "País vasto, de população escassa, disseminada, a que falta até a instrução primária, não oferece outra base para $o$ regime representativo, senão a da influência que em cada região possam ter os poucos homens que por

\footnotetext{
${ }^{12}$ PEREIRA, Osny Duarte. Que é Constituição (crítica à Carta de 1946 com vistas a reformas de base). Rio de Janeiro: Civilização Brasileira, 1964, p. 5.

${ }^{13}$ Apud FERREIRA, Jorge; e GOMES, Ângela Castro, 1964: o golpe que derrubou um presidente, pôs fim ao regime democrático e instituiu a ditadura no Brasil. Rio de Janeiro: Civilização Brasileira, 2014, p. 273.

${ }^{14}$ GUANABARA, Alcindo. A presidência Campos Sales. Brasília: UnB, 1983. p. 62-63.
}

condições de educação ou de fortuna exerçam sobre esses povos uma influência que lhes é ordinariamente benéfica e a que eles se submetem sem querer, nem poder analisá-la nas suas consequências e efeitos" ${ }^{14}$. O poder do povo deveria ser exercido pelas oligarquias, até que o desenvolvimento econômico trouxesse consigo a transformação social. Antes disso, de nada adiantaria reformar o sistema, atitude que, ao contrário, poderia comprometer a ordem necessária à modernização. Por outro lado, revoltados com a inefetividade das instituições liberais democráticas, os progressistas alijados da participação política a atribuíram à maldade, à corrupção e à falta de civismo da classe política. O problema era moral: "No terreno das coisas públicas, entre nós, a mentira constitui o instrumento, por excelência, da usurpação da soberania nacional pela oligarquia da União, pelas oligarquias dos Estados, pelas oligarquias das municipalidades. Cada uma delas mente, assumindo o nome do regime constitucional, que absorveu, e matou", declarava Rui Barbosa em $1919^{15}$. Mas a sociedade civil também tinha sua parcela de culpa, "pela sua abstenção, pela sua frouxidão, pela sua desorganização", ele acrescentava ${ }^{16}$. A mesma crítica seria repetida e generalizada um século depois por outro jurista constitucional, Luís Roberto Barroso. Pela falta de espírito cívico dos políticos brasileiros e suas elites egoístas, "as Cartas brasileiras sempre se deixaram inflacionar por promessas de atuação e pretensos direitos que jamais se consumaram na prática" ${ }^{\prime 17}$.

${ }^{15}$ BARBOSA, Rui. Campanhas Presidenciais. v. IV. São Paulo: Iracema, s/d, p. 169.

${ }^{16}$ Idem, ibidem, p. 143.

${ }^{17}$ BARROSO, Luís Roberto; BARCELLOS, Ana Paula de. O Começo da História: a Nova Interpretação Constitucional e o Papel dos Princípios no Direito Brasileiro. Interesse Público, v. 5, n. 19, p. 51-80, 2003. 
TERCEIRO

DIAGNÓSTICO: ADIANTAMENTO DEMASIADO DO PAÍS LEGAL DIANTE DO REAL

A terceira e última percepção possível era a de que as instituições (país legal) estariam demasiado adiantadas em relação às necessidades do estado social (país real). Nesse caso, a reação era no sentido de se demandarem reformas capazes de, levando em consideração a especificidade da sociedade periférica, reduzir o hiato entre o idealismo das instituições estrangeiras e a realidade periclitante da vida nacional. Esse foi o caso dos conservadores na época do Regresso (1837-1843), como Bernardo de Vasconcelos e Lopes Gama. A causa da desordem e das guerras civis residia nas instituições liberais adotadas no Brasil, baseadas em doutrinas cêntricas de caráter metafísico, adotadas sem atenção às circunstâncias nacionais: "Transplantamos para o Brasil legislações exóticas acomodadas a outros costumes e condições sociais, e ficamos em pior estado do que estávamos", sentenciava Lopes Gama em $1839^{18}$. Em 1930, os nacional-reformistas da Primeira República reiterariam a crítica de Vasconcelos e Lopes Gama: inspiradas por um cosmopolitismo estrangeiro e por um teorismo abstrato, as elites insistiam em ministrar ao Brasil fórmulas vãs de desconcentração do poder, quando, ao contrário, deveriam voltar-se para o estudo da realidade nacional, e perceber que do que se precisava era de fortalecer o Estado para construir a nação. "Os nossos construtores de Constituições têm sido espíritos idealistas, que desconhecem por inteiro o meio e o povo para os quais legislam", explicava Oliveira Viana ${ }^{19}$. Nasceria assim de tais autores outro tema famoso da cultura política brasileira, relativo ao idealismo

\footnotetext{
${ }^{18}$ ANAIS do Senado do Império, sessão de 18 de maio de 1839.

19 VIANA, Francisco José de Oliveira. Problemas de Política Objetiva. Rio de Janeiro: Record, 1974, p. 46.
}

utópico da nossa elite, que deveria ser substituído por um idealismo orgânico, baseado na observação e na experiência.

\section{A FRUSTRAÇÃO EM TORNO DA MODERNIZAÇÃO INSTITUCIONAL: O PEDAGOGISMO}

A frustração, portanto, com o estado nacional, decorrente do hiato entre as modernas instituições importadas dos países julgados modelares em matéria de progresso e seu desempenho precário no mundo social brasileiro, levou frequentemente à irrupção de outros dois temas típicos da cultura política periférica: o do pedagogismo e o das vanguardas modernizadoras. Ambos estão relacionados com a presunção, que existe na periferia, de que não são as instituições que devem refletir o estado social do país; e sim que é o estado social - inferior, decaído, atrasado - que deve ser modificado por meio da ação das elites, para que se alcance o nível das instituições políticas importadas. O tema do pedagogismo é relativo à necessidade de se educar as elites ou a população para a prática das instituições modernas, sem o quê as instituições políticas permaneceriam inefetivas. $\mathrm{O}$ mais célebre pedagogo brasileiro foi Rui Barbosa que, reputado pai da Constituição de 1891, passou a entender ser seu dever esforçar-se por educar as elites políticas e jurídicas na prática das instituições livres nela consagradas: "É nas classes mais cultas e abastadas que devem ter o seu ponto de partida as agitações regeneradoras. Demos ao povo o exemplo, e ele nos seguirá" ${ }^{20}$. No entanto, o pedagogismo não foi apanágio dos liberais, mas também dos nacional-reformistas. Para Oliveira Viana, era preciso educar as elites para o sentido coletivo da existência, nelas

${ }^{20}$ BARBOSA, Rui. Ruínas de um Governo: o governo Hermes, as ruínas da Constituição, a crise moral, a justiça e manifesto à Nação. Prefácio e notas de Fernando Néri. Rio de Janeiro: Guanabara, 1931. p. 140. 
incutindo o hábito de servir à Nação, no sentido anglo-saxão do termo ${ }^{21}$. À esquerda também se poderia verificar a presença do pedagogismo. Em 1967, Roland Corbisier explicava que o fracasso do movimento pelas reformas de base durante a presidência Goulart se dera porque "faltava aos próprios reformistas formação ideológica e clara consciência do problema" ${ }^{22}$. O pedagogismo traduz assim a noção de que o atraso da nação se deve ao despreparo da sociedade para assimilar os ideais que a conduzirão e ao país à modernidade característica dos países cêntricos.

\section{REAÇÃO À CRISE DE LEGITIMIDADE DA POLÍTICA TRADICIONAL: VANGUARDAS MODERNIZADORAS}

Já o segundo tema, o das vanguardas modernizadoras, está ligado também ao "processo de desilusão" com o processo de desenvolvimento político de cunho meramente institucional, a que se referia Sílvio Romero. Descrentes de que o povo ou a sociedade civil sejam capazes de conduzir à modernização do país pelas vias naturais da evolução liberal democrática, desentravando os obstáculos ao progresso, diversos grupos se investiram ao longo do tempo do papel de vanguardeiros ou porta-vozes do moderno, elaborando projetos nacionais alternativos, destinados a alavancar o processo de desenvolvimento, conforme o ideal de modernidade que tinham em mente. As vanguardas pulularam especialmente em momentos de crise do sistema políticoconstitucional, quando o vácuo de legitimidade da classe dirigente abre brechas para a emergência de outros atores, "não-profissionais", com pretensões de liderança, bem como dos projetos alternativos de desenvolvimento de que seriam os portadores privilegiados. Essas vanguardas

21 VIANA, Francisco José de Oliveira. Problemas de Organização, Problemas de Direção. Intr. Hermes Lima. Rio de Janeiro: Record, 1974. p. podem no Brasil ser diferentemente classificadas, conforme estejam localizadas no interior do Estado ou da sociedade civil. As mais importantes têm sido aquelas situadas no âmbito do próprio Estado, graças ao peso da burocracia na história nacional. A importância de uma tecnocracia ilustrada para servir de suporte à ação progressista do governante seria reafirmada por um sem número de intelectuais, como Euclides da Cunha, Vicente Licínio Cardoso, Hélio Jaguaribe e Guerreiro Ramos. No âmbito da sociedade civil, diversos dos seus segmentos se apresentaram como a corporificação por excelência da Nação, dispondo inclusive de intelectuais orgânicos, como os fazendeiros (Tavares Bastos), os industriais (Azevedo Amaral), os bacharéis (Rui Barbosa), os intelectuais do partido comunista (Caio Prado Jr.) etc. Não havendo aqui espaço para referir-me a cada uma delas, me centrarei nas três mais importantes, que eram aquelas vinculadas ao Estado.

\section{AS VANGUARDAS BUROCRÁTICAS (1): O GOVERNANTE}

Sintonizado com os ideais do reformismo ilustrado, o mais antigo discurso "vanguardeiro" da burocracia do Estado prescreve que o próprio chefe de governo, apoiado por um grupo de tecnocratas esclarecidos, deveria agir como o motor por excelência da modernização nacional, devendo-se-lhe delegar o poder necessário para derrotar os obstáculos à sua promoção. No século XIX, integraram este grupo políticos conservadores como José Bonifácio, o Barão de Santo Ângelo e o Visconde de Uruguai, que reivindicaram o poder da Coroa de criação e manutenção da ordem nacional, mas também liberais como Joaquim Nabuco e positivistas como Miguel Lemos e Teixeira Mendes, que

${ }^{22}$ CORBISIER, Roland. Reforma ou revolução? Rio de Janeiro: Civilização Brasileira, 1968, p. 2. 
apelaram ao poder pessoal do chefe de Estado para que o empregassem como um instrumento de modernização da sociedade brasileira. No século $\mathrm{XX}$, a apologia do poder pessoal do governante voltaria pelas mãos dos intelectuais que davam sustentação à direção impressa por Getúlio Vargas durante o Estado Novo, como Monte Arrais, Oliveira Viana, Francisco Campos e Azevedo Amaral. Como se percebe, a tese de que o governante seria o principal agente da modernização na periferia não é necessariamente autoritária, nem privativa da direita. Ela permanece nos regimes democráticos dos países periféricos, expressa na defesa do sistema de governo presidencialista, justificado como instrumento indispensável para o enfrentamento com uma classe política comprometida com os interesses conservadores, encastelada no poder legislativo. Neste sentido, a tese do governante como vanguarda transpôs as fronteiras da burocracia para tornar-se, no período de democratização do sistema político brasileiro, a pedra de toque do sindicalismo e do corporativismo brasileiros, conforme demonstram o prestígio que junto aos trabalhadores gozaram Getúlio Vargas, João Goulart e, recentemente, Luís Inácio Lula da Silva.

\section{AS VANGUARDAS BUROCRÁTICAS (2): OS MILITARES}

Entretanto, conforme foram se especializando e ganhando autonomia relativa do governante enquanto corporações, os magistrados e os militares passaram a concorrer com ele na condição de vanguarda, entendida como verdadeira depositária do interesse público. $\mathrm{O}$ mais célebre grupo burocrático a reivindicar $o$ papel de "vanguarda iluminista" foi, sabe-se, os militares. Desde o final do Império, porta-vozes deles de inspiração positivista e jacobina, como Benjamin Constant e Lauro Sodré, passaram a veicular a tese de que os soldados seriam "cidadãos fardados": os militares seriam os mais patrióticos de todos os cidadãos; os únicos dotados de, num ambiente de decadência cívica da classe política civil (a "pendantocracia") e da apatia do povo, darem a vida pela Pátria. Por esses motivos, sua obediência ao governo dependeria da legalidade de suas ordens, interpretada pelos próprios militares segundo seus representantes abalizados (geralmente, o Clube Militar). Esta ideologia teve papel importante no golpe republicano de 1889; desde então, os militares não mais cessaram de imaginar-se os tutores da felicidade do novo regime. Embora basicamente restrita à mocidade militar durante a Primeira República, o ideário salvacionista voltou a manifestar-se durante a presidência do marechal Hermes da Fonseca. A mocidade militar ressuscitaria em seu ímpeto revolucionário na década de 1920 com o movimento tenentista, cujos principais intérpretes foram Juarez Távora e Virgínio Santa Rosa, que descreviam o exército como porta-voz das aspirações nacionais. Entre 1930 e 1945, inverteu-se a equação: generais protofascistas, como Góis Monteiro, passaram a veicular a tese de que o Exército, ao revés, é que deveria servir de espelho à reorganização nacional. Restabelecido o regime liberaldemocrático no contexto da guerra fria, militares como Golbery do Couto e Silva pregavam nas décadas de 1950 e 1960 que a política brasileira deveria se submeter às exigências da segurança nacional, destinada a salvaguardar o desenvolvimento do país contra a ameaça do comunismo. Na qualidade de defensores dos interesses nacionais permanentes contra os políticos profissionais, os militares intervieram na política brasileira em 1937, 1945, 1954, 1955, 1961 e 1964, quando tomaram o poder com ânimo de permanência. Os vinte anos de regime militar, com sua prática de tortura sistemática aos adversários e descalabro econômico dos últimos 
anos, encarregaram-se de sepultar a ideologia do soldado-cidadão, que afinal desapareceu.

\section{AS VANGUARDAS BUROCRÁTICAS (3): A MAGISTRATURA E O MINISTÉRIO PÚBLICO}

Com o fim do domínio militar e a redemocratização do país, os militares foram paulatinamente substituídos na condição de vanguarda burocrática pelos magistrados e promotores, especialmente os da esfera federal. A despeito da pregação de um Pedro Lessa neste sentido já na década de 1910, a posição do juiz constitucional como a de um guardião do Estado de direito permaneceu latente depois de 1930, quando, esperava-se, haveria de se realizar. A causa, claro, foi a concorrência desleal promovida pelos militares, que se investiram daquela missão, em detrimento dos magistrados e dos bacharéis. A hora e a vez do Judiciário chegaria somente com a promulgação da Constituição de 1988, quando a centralidade e a independência assumida pela magistratura e pelo ministério público, principalmente a federal, de um lado, e a ascensão do paradigma neoconstitucionalista criou condições objetivas para a implementação de suas aspirações de protagonismo na cena política. Segundo os defensores desta orientação, o magistrado e promotor público deveriam orientar a sua ação conforme um ativismo constitucional, que os erigissem à condição de substitutos processuais da própria sociedade civil na consecução de uma sociedade "republicana", contra a inépcia e a corrupção da classe política. A reivindicação para a magistratura de uma posição vanguardeira têm sido desde então justificada por sociólogos como Luiz Werneck Viana e juristas como Gilmar Mendes, Joaquim Barbosa e Luís Roberto Barroso. Recentemente, este último declarou que, diante da decadência dos costumes públicos, a crise do sistema representativo e o histórico de inefetividade constitucional, o juiz constitucional teria hoje de assumir uma função de vanguarda no Brasil: “Às vezes, é preciso uma vanguarda iluminista para empurrar a história. É isso que legitima o nosso papel"23.

\section{IDEOLOGIAS POLÍTICAS BRASILEIRAS}

Uma cultura política é atravessada por diversos discursos, práticas simbólicas ou ideologias orientadas por diferentes valores e/ou interpretações da realidade. Os fatos políticos precisam ser interpretados à luz dos valores, crenças, interesses e objetivos dos diversos segmentos de que a sociedade é composta. As ideologias ou discursos de uma cultura política apresentam três características funcionais: servem de mapas para que indivíduos e grupos sociais se orientem meio à complexidade e à opacidade do mundo; são defendidas por grupos identificáveis que disputam a preferência daqueles que detém o poder; e almejam justificar, contestar e transformar os arranjos e processos sociais e políticos. São metáforas, símbolos e temas prenhes de significados, atravessados por narrativas sobre o passado, o presente e o futuro da comunidade, que objetivam ordenar a sua realidade no espaço e no tempo. As ideologias ou discursos políticos também revelam a capacidade de se adaptar às mudanças sociais, ao mesmo tempo em que reivindicam uma tradição, composta de antecessores, verdadeiros ou inventados, na forma de mártires, doutrinadores ou heróis. Olhando pelas denominações clássicas e formais, a cultura política brasileira é atravessada pelo mesmo leque de ideologias existentes alhures - conservadorismo, liberalismo e socialismo -, nas suas mais diversas subdivisões. Entretanto, quando encaradas do ponto de vista substantivo e levando em consideração a longa duração, os estudiosos da

${ }^{23}$ O GLOBO, edição de 14 de dezembro de 2013, p. 2. 
cultura política brasileira são unânimes em reconhecer a predominância de duas grandes tradições intelectuais e ideológicas, desde a independência do país: o nacional-estatismo, de caráter realista e culturalista, e o liberalismo cosmopolita, de caráter idealista e universalista. Sob diferentes denominações, o nacional estatismo e o cosmopolitsmo liberal viriam se adaptando ao longo do tempo às mudanças da cultura política verificadas nos países cêntricos, de um lado, e àquelas sofridas pela sociedade brasileira.

\section{IDEOLOGIAS POLÍTICAS NACIONAL-ESTATISMO}

(1):

$\mathbf{O}$

A tradição nacional-estatista é tributária do reformismo ilustrado e do projeto imperial acalentado pelos fundadores do Império. Ela parte de um diagnóstico negativo da formação nacional brasileira, marcada pela inorganicidade, pela pobreza, pela ignorância, pelo caudilhismo e pela ausência de vínculos de solidariedade cívica nacional. Diante da fraqueza da sociedade nacional e dos perigos desta fraqueza para a nacionalidade brasileira, num mundo no qual a ameaça do imperialismo é constante, o Estado nacional deve se investir da condição de motor do desenvolvimento, gozando de certa autonomia decisória e intervindo no domínio socioeconômico. Estas seriam as condições necessárias para que ele pudesse produzir a ordem, a liberdade e a igualdade de que a comunidade seria carente e reduzir, desta forma, a distância que separaria o Brasil dos países desenvolvidos ou "cêntricos". Para se desempenhar dessa missão, o Estado nacional se orientar de forma nacionalista, valorizando a identidade nacional contra o colonialismo estrangeiro no exterior e contra as fidelidades provinciais ou municipais no interior. Essa diretriz impõe, de um lado, a centralização do poder político na capital e o predomínio do Poder
Executivo sobre o Legislativo; de outro, o apelo ao planejamento econômico e à nacionalização de setores estratégicos da economia. Neste caso, recorre-se inclusive à estatização e ao incentivo às indústrias, seja com redução de impostos, seja com empréstimos a juro baixo. Esta tem sido nos últimos dois séculos a ideologia preferida das vanguardas burocráticas, como os cortesãos, os tecnocratas, os militares e os magistrados/promotores. Depois de 1930, passou a angariar também a simpatia da maior parte dos industriais, dos sindicatos e de parcelas expressivas da população.

$\mathrm{Na}$ história brasileira, o nacional-estatismo teve três reconhecidos períodos de hegemonia. $\mathrm{O}$ primeiro deles correspondeu à primeira metade do reinado de Dom Pedro II, quando se consolidou o Estado nacional por meio do modelo político "saquarema" teorizado por Bernardo de Vasconcelos e pelo Visconde de Uruguai (18371868). O segundo deles se iniciou em 1930 e se concluiu em torno de 1980, subdividindo-se em três fases: a) a chamada Era Vargas, quando se deu o entrecruzamento autoritário do nacional reformismo de Alberto Torres com o industrialismo de Roberto Simonsen e o sindicalismo corporativo de Oliveira Viana (1930-1945); b) o período da república democrática de 1946, quando o modelo varguista foi adaptado pela coalizão de centro-esquerda que sustentou o segundo governo Vargas e Juscelino Kubitschek, como um "nacionaldesenvolvimentismo" teorizado por intelectuais como Hélio Jaguaribe, Guerreiro Ramos e Celso Furtado, que acabou colapsando pela radicalização das esquerdas sob o governo Goulart (1945-1964); e c) o período do regime militar, quando o nacional-estatismo em versão autoritária (embora associado ao capital estrangeiro) encontrou o seu apogeu, durante as presidências de Emílio Médici e Ernesto Geisel (1964-1979). O terceiro período corresponde à atualidade, quando, durante as presidências Lula 
da Silva e Dilma Rousseff, as práticas nacionalestatistas foram recuperadas e teorizadas por intelectuais como Márcio Pochmann com o nome de "social-desenvolvimentismo", porque buscaria conciliar crescimento econômico e justiça social, trazendo consigo não apenas os sindicatos como os movimentos sociais (2002-2014).

\section{IDEOLOGIAS POLÍTICAS LIBERALISMO COSMOPOLITA}

(2).

O liberalismo cosmopolita se contrapõe frontalmente ao nacional-estatismo, deslocando a centralidade do Estado existente naquela ideologia para colocar em seu lugar a sociedade civil e o mercado como motores do desenvolvimento do país. Para tanto, os liberais, ou negam o diagnóstico nacional-estatista de fragilidade da sociedade civil brasileira, reivindicando a sua força e sua capacidade de autodeterminação, ou reconhecem a sua fraqueza, imputando-a, porém, ao peso excessivo do Estado na vida nacional. Num caso ou no outro, o peso do governo deve ser reduzido para que a sociedade civil e o mercado tenham condições de se desenvolver com liberdade. Aspira-se por um
Estado que opere com plena transparente frente à sociedade e vigiado por ela, característica que, do ponto de vista político-institucional, exprime-se pela predileção por fórmulas de dispersão do poder, seja pelo federalismo, seja pelo municipalismo, bem como pela criação de mecanismos antimajoritários, como a jurisdição constitucional e o parlamentarismo. $\mathrm{O}$

O nacionalismo é rejeitado como símbolo do atraso e do autoritarismo, acreditando-se que apenas o estreitamento da cultura brasileira com aquelas dos países cêntricos poderá reduzir a negatividade da formação nacional originária. A crença do liberal no espontaneísmo e na autorregulação da sociedade e do mercado o levam a acreditar que a abertura do capital estrangeiro, a redução das tarifas alfandegárias levará a um regime de maior competitividade econômica, abrindo-se mão do sonho nacional-estatista de grandeza nacional, devendo o país enquadrar-se numa divisão internacional do trabalho, favorecendo os produtos em que leva vantagem comparativa. Esta tem sido historicamente a ideologia favorita dos senhores de engenho, dos fazendeiros, dos bacharéis e dos profissionais liberais em geral.

\section{REFERENCIAS}

ANAIS do Senado do Império do Brasil. Rio de Janeiro/Brasília, 1826-1889. Disponível em: < www.senado.gov.br >.

BARBOSA, Rui. Campanhas Presidenciais. v. IV. São Paulo: Iracema, s/d.

. Correspondência. Coligida, revista e anotada por Homero Pires. São Paulo: Saraiva, 1932.

. Ruínas de um Governo: o governo Hermes, as ruínas da Constituição, a crise moral, a justiça e manifesto à Nação. Prefácio e notas de Fernando Néri. Rio de Janeiro: Guanabara, 1931.

BARROSO, Luís Roberto; BARCELlOS, Ana Paula de. O Começo da História: a Nova Interpretação Constitucional e o Papel dos Princípios no Direito Brasileiro. Interesse Público, v. 5, n. 19, p. 51-80, 2003.

BASTOS, Aurelino Cândido Tavares. Cartas do Solitário. São Paulo: Companhia Editora Nacional, 1976. 
CAMPOS, Francisco. O Estado Nacional: sua estrutura, seu conteúdo ideológico. $3^{\text {a }}$. edição. Rio de Janeiro: Livraria José Olímpio, 1941.

CORBISIER, Roland. Reforma ou revolução? Rio de Janeiro: Civilização Brasileira, 1968.

FERREIRA, Jorge; GOMES, Ângela Castro, 1964: o golpe que derrubou um presidente, pôs fim ao regime democrático e instituiu a ditadura no Brasil. Rio de Janeiro: Civilização Brasileira, 2014.

GUANABARA, Alcindo. A presidência Campos Sales. Brasília: UnB, 1983.

O GLOBO.

PEREIRA, Osny Duarte. Que é Constituição (crítica à Carta de 1946 com vistas a reformas de base). Rio de Janeiro: Civilização Brasileira, 1964.

PESSOA, Epitácio. Conferência da Paz, Diplomacia e Direito Internacional. Obras completas de Epitácio Pessoa, volume XIV. Rio de Janeiro: Instituto Nacional do Livro, 1961.

PRADO, Eduardo. Destinos políticos do Brasil. Revista do Instituto Histórico e Geográfico Brasileiro. Anais do Congresso de História do Segundo Reinado. v. II. Rio de Janeiro: 1984.

PRADO, Paulo. Paulística, etc. Organização de Carlos Augusto Calil. São Paulo: Companhia das Letras, 2004.

VIANA, Francisco José de Oliveira. Problemas de Organização, Problemas de Direção. Intr. Hermes Lima. Rio de Janeiro: Record, 1974.

. Problemas de Politica Objetiva. Rio de Janeiro: Record, 1974.

Recebido em: 30/08/2017

Aceito em: 30/08/2017 
